\title{
Examining the Novelty, Interactivity and User-Friendly Attributes of Virtual Laboratory Package For Conducting Nigerian Secondary School Physics Experiments
}

\author{
Dr. Falode Oluwole Caleb* \\ Department of Educational Technology, Federal University of Technology, Minna, Nigeria \\ Email: facominsight2@gmail.com
}

\section{Ojo Ranti Francis}

Department of Science Education, Veritas University, Abuja, Nigeria

\section{Fadipe Bayo Michael}

Department of Science Education, Veritas University, Abuja, Nigeria

\section{Omodara Oladele Dennis}

Department of Educational Technology, University of Education, Science and Technology, Ikere-Ekiti, Nigeria

\author{
Article History \\ Received: November 3, 2020 \\ Revised: December 2, 2020 \\ Accepted: December 5, 2020 \\ Published: December 8, 2020
}

\begin{abstract}
The study assessed the novelty, interactivity and user-friendly attributes of a developed virtual laboratory package for conducting Nigerian secondary school physics experiments. Descriptive survey design was employed and answers were provided to three research questions. Purposive sampling technique was used to select 22 instructional design experts and 35 computer experts who examined and rated the package using adapted questionnaires that were validated and found reliable for data collection. Data gathered from the administration of the questionnaires were analyzed using Mean and Standard deviation. Findings revealed that computer experts agreed that learning through virtual laboratory is an innovation that is new to physics students and teachers in Nigerian secondary schools (average mean response $=2.61$ out of 5), instructional design experts rated the interactivity features of the package low (average mean response $=2.32$ out of 5), but agreed that the package possess user-friendly features (average mean response $=2.80$ out of 5). Based on these findings, it was recommended among others that, developers of learning packages such as virtual physics laboratory package should ensure high interactivity and friendliness of the packages in order to improve students' achievement, enhance effective communication and foster their interest in physics contents.
\end{abstract}

Keywords: Interactivity; Novelty; Physics; User friendliness; Virtual laboratory.

\section{Introduction}

The technological development of any nation lies in the study of science. One of the core science disciplines is Physics. The discipline has proven its benefits to mankind as almost every human activity and virtually every profession involves some element of physics (Falode, 2014; Javed, 2005). The fields of medicine, engineering, communication technology, architecture, geophysics, biophysics, material sciences, nuclear physics, agronomy among several others, are based on the fundamental principle of physics (Okoro, 2003). Therefore, physics is included in the Nigerian senior secondary school science curriculum to build strong technological foundation for students.

One important aspect of physics is mechanics. The importance attached to mechanics topics in physics as underscored by West African Examination Council (2002-5) of West African Examinations Council (WAEC) indicated that more than 30 percent of senior secondary school physics examination questions were from mechanics and that the poor performance in physics recorded on the concepts of mechanics are mainly in the areas of elasticity properties of solid, kinetic theory, simple harmonic motion, projectiles motion, relative density of a solid, properties of matter, equilibrium of forces and mechanical energy, simple mathematical computation, interpretation of expressions and equations affected students' performance in this aspect of physics (Rafiu and Adetona, 2006). Hence, virtual physics laboratory on simple pendulum, Hooke's law and momentum experiments was developed by the researchers to tackle some of the difficulties students encounter while learning those concepts under mechanics.

Virtual laboratory is an interactive environment without real laboratory tools meant for creating and conducting simulated experiments (Babateen, 2011; Harry and Edward, 2005). In science and engineering education, virtual laboratories have emerged as alternative or supplementary tools of the hands-on laboratory education (Falode and Gambari, 2017). It provides students with tools and materials set on computer in order to perform experiments saved on CDs or on website and it has been proven to improve students' performance in science based subjects globally (Babateen, 2011; Nunn, 2009). Researchers through various studies reported students' improved academic performance in science-based subjected when exposed to virtual laboratories (Falode and Onasanya, 2015; Mahmoud and Zoltan, 2009; Murniza et al., 2010).

*Corresponding Author 


\section{Sumerianz Journal of Education, Linguistics and Literature}

As effective as they have been found out to be in teaching and learning process, virtual laboratory instruction should be developed based on constructivist learning approach. Cooperstein and Kocevar-Weidinger (2004), opined that in constructive learning, the standard classroom procedure is turned upside down because there are no lectures, no demonstrations, and no presentations. That is, from the beginning, students engage in activities through which they develop skills and acquire knowledge. In other words, students' active engagement and interaction with the simulation tool is essential for learning to take place.

According to Bates (1995), the novelty, in other words, newness, the interactive features and user-friendly attributes of a learning package should be examined. Novelty deals with the newness of a particular technology and the technical capabilities to use such innovation, get accessories and tools for. Interactivity of a learning package such as virtual laboratory implies the extent to which a learner is able to satisfactorily connect with the learning content, fellow learners and instructor (Falode, 2014). Babateen (2011), was of the opinion that virtual laboratory package should be distinctively interactive and have unique sorts of interaction better than traditional multi-media. Dillon (2007) added that, to achieve quality in teaching and learning in education, especially in science-based subjects, learning resources and activities should be made very interactive, attractive and interesting in order to attract students' attentions and urge them to complete the experiment.

There exists danger that multimedia and other emerging technologies are being used in teaching and learning process simply because they are available without an appropriate conceptual framework to guide their selection, hence, intended objectives may not be achieved. Therefore, this study was carried out to examine how new the technology is to students and staff in Nigerian secondary schools; to determine if learners are able to interact with their teachers, colleagues and the content as expected, and to determine if the package is easy for learners' usage while conducting physics experiments.

\subsection{Research Questions}

The following research questions guided the study:

1. What is the mean ratings of computer experts on the newness of virtual laboratory package to physics students and teachers in Nigerian secondary schools?

2. What is the mean rating of instructional design experts on the interactivity features of virtual laboratory package for conducting secondary school physics experiments?

3. What is the mean rating of instructional design experts on the user-friendly attributes of virtual laboratory package for conducting secondary school physics experiments?

\section{Methodology}

The study adopted a descriptive survey research approach in which questionnaire was used to elicit needed information from relevant specialists - instructional design experts and computer experts who examined and rated the novelty, interactivity and user-friendly attributes of a researchers-developed virtual laboratory package for conducting secondary school physics experiments.

The population for this research consists of all instructional design experts and all computer experts in Nigeria. Twenty-two instructional design experts and thirty-five computer experts were purposively selected from six Federal Government Colleges in south-west, Nigeria because of their relevance to the evaluation to be carried out.

Three research instruments were used for the study. They are virtual physics laboratory package, Evaluation Questionnaire for Instructional Design Experts (EQIDE) and Evaluation Questionnaire for Computer Experts (EQCE). The questionnaires were used by experts to rate the attributes of the package in terms of novelty, interactivity, user-friendly features.

The virtual laboratory package was developed using Adobe Flash CS6. Actions script 3.0 was used for the programming language while Adobe Fireworks CS6 was used to create the Graphic User Interface (GUI). Also, Box2D was used for the physics simulation engine and CamStudio software was used in recording the video tutorial. The package is meant for performing three SSII physics experiments (simple pendulum experiment, Hooke's law experiment and momentum experiment). The entrance menu of the package consisted of introduction/student's registration edifice, list of practical lessons (Lessons 1, $2 \& 3$ ) and exit button. The main menu is divided into three sections, namely, lesson note section, where the learner is able to study the content for the experiments; Video section, where the learner is able to watch tutorial of how to use the package; and laboratory section where the learner is able to perform the experiments virtually.

EQIDE (consisting three items on interactive features and nine items on user-friendlly attributes of the package) and EQCE (four items on novelty attributes of the package) were designed to collect data from the experts based on their rating of the package. Both questionnaires were adapted from Atsloom (2009) using 4-point scale (namely, 1 as Strongly Disagree, 2 as Disagree, 3 as Agree and 4 as Strongly Agree). The instruments were validated by experts and the reliability of EQIDE and EQCE were determined in a single administration on five educational technology experts. Cronbach alpha formula yielded reliability coefficient of 0.90 and which yielded a reliability coefficient of 0.90 and 0.93 for the two instruments respectively. The three research questions were answered using descriptive statistics of Mean and Standard Deviation. A mean response of 2.50 and above was considered Agreed while mean response below 2.50 was considered Disagreed to the questionnaire items used to answer the research questions.

\section{Results}

Research Question 1: What is the mean ratings of computer experts on the newness of virtual laboratory package to physics students and teachers in Nigerian secondary schools? 
Sumerianz Journal of Education, Linguistics and Literature

Table-1. Mean response of computer experts on novelty of the virtual laboratory package

\begin{tabular}{l|l|l|l|l|l|l|l|l|l}
\hline S/N & Statement & N & SA & A & D & SD & Mean & S. Dev. & Decision \\
\hline 1 & $\begin{array}{l}\text { The concept of virtual physics } \\
\text { laboratory is a new idea in my } \\
\text { school }\end{array}$ & 35 & 12 & 8 & 7 & 8 & 2.68 & 0.18 & Agree \\
\hline 2 & $\begin{array}{l}\text { Virtual physics laboratory package } \\
\text { is new to physics students in my } \\
\text { school }\end{array}$ & 35 & 12 & 13 & 4 & 6 & 2.88 & 0.38 & Agree \\
\hline 3 & $\begin{array}{l}\text { Virtual physics laboratory package } \\
\text { is new to physics teachers in my } \\
\text { school }\end{array}$ & 35 & 11 & 10 & 8 & 6 & 2.74 & 0.24 & Agree \\
\hline 4 & $\begin{array}{l}\text { Virtual physics laboratory package } \\
\text { is a new and innovative ICT } \\
\text { approach for learning science- } \\
\text { based subjects in my school. }\end{array}$ & 35 & 5 & 6 & 13 & 11 & 2.14 & 0.35 & Disagree \\
\hline & Average Mean & & & & & & $\mathbf{2 . 6 1}$ & & \\
\hline
\end{tabular}

Table 1 reveals the mean response of computer experts on the novelty of the virtual laboratory package. The table reveals that the mean response of respondents to each of the items is above 2.50 except item 4 with a mean response of 2.14. The average mean response of the four items is 2.61 . This indicates that the respondents agreed that the use of virtual physics laboratory package for conducting physics experiment is a new innovation in secondary schools in Nigeria.

Research Question 2: What is the mean rating of instructional design experts on the interactivity features of virtual laboratory package for conducting secondary school physics experiments?

Table-2. Mean response of instructional design experts on the interactive features of the virtual laboratory package

\begin{tabular}{l|l|l|l|l|l|l|l|l|l|l}
\hline S/N & Statement & N & SA & A & D & SD & Mean & S. Dev. & Decision \\
\hline 1 & $\begin{array}{l}\text { Virtual physics laboratory package } \\
\text { enables learner-to- learner interaction } \\
\text { while conducting simple pendulum, } \\
\text { Hooke's law and momentum } \\
\text { experiments }\end{array}$ & 22 & 3 & 5 & 6 & 8 & 2.13 & 0.37 & Disagree \\
\hline 2 & $\begin{array}{l}\text { Virtual physics laboratory package } \\
\text { enables learner-to-content interaction } \\
\text { while conducting simple pendulum, } \\
\text { Hooke's law and momentum } \\
\text { experiments }\end{array}$ & 22 & 8 & 5 & 4 & 5 & 2.72 & 0.22 & Agree \\
\hline 3 & $\begin{array}{l}\text { Virtual physics laboratory package } \\
\text { enables learner-to-tutor interaction } \\
\text { while conducting simple pendulum, } \\
\text { Hooke's law and momentum } \\
\text { experiments }\end{array}$ & 22 & 4 & 4 & 5 & 9 & 2.13 & 0.36 & Disagree \\
\hline & Average Mean & & & & & & & $\mathbf{2 . 3 2}$ & & \\
\hline
\end{tabular}

Table 2 shows the mean response of instructional design experts on the interactivity of the virtual laboratory package. The mean response of experts to item 1 (learner-to-learner interactivity of the package) and item 3 (learnerto-tutor interactivity of the package) is 2.13 each while the mean response of experts to item 2 (learner-to-content interactivity of the package) is 2.72 . The average mean of the responses to the three items is 2.32 which is below 2.50. This indicates that instructional design experts disagreed that the virtual physics laboratory package is interactive.

Research Question 3: What is the mean rating of instructional design experts on the user-friendly attributes of virtual laboratory package for conducting secondary school physics experiments?

Table-3. Mean responses of instructional design experts on user-friendly features of virtual laboratory package

\begin{tabular}{l|l|l|l|l|l|l|l|l|l|l}
\hline S/N & Statement & N & SA & A & D & SD & Mean & S. Dev. & Decision \\
\hline 1 & $\begin{array}{l}\text { Buttons and icons in the } \\
\text { package make virtual physics } \\
\text { laboratory package easy to } \\
\text { use }\end{array}$ & 22 & 9 & 6 & 4 & 3 & 2.95 & 0.45 & Agree \\
\hline 2 & $\begin{array}{l}\text { Instructions in the virtual } \\
\text { physics laboratory package } \\
\text { are easy to comprehend }\end{array}$ & 22 & 8 & 8 & 4 & 2 & 3.00 & 0.50 & Agree \\
\hline 3 & $\begin{array}{l}\text { Content and procedure in the } \\
\text { virtual physics laboratory } \\
\text { package are arranged from } \\
\text { simple to complex, known to }\end{array}$ & 22 & 6 & 7 & 6 & 3 & 2.72 & 0.22 & Agree \\
\hline
\end{tabular}




\begin{tabular}{l|l|l|l|l|l|l|l|l|l}
\hline & unknown & & & & & & & & \\
\hline 4 & $\begin{array}{l}\text { Procedures and contents in } \\
\text { the virtual physics laboratory } \\
\text { package are suitable to } \\
\text { students' need and level }\end{array}$ & 22 & 8 & 9 & 2 & 3 & 3.00 & 0.50 & Agree \\
\hline 5 & $\begin{array}{l}\text { Virtual physics laboratory } \\
\text { package has detailed user and } \\
\text { operational manual }\end{array}$ & 22 & 6 & 4 & 7 & 5 & 2.50 & 0.00 & Agree \\
\hline 6 & $\begin{array}{l}\text { Virtual tools and equipment } \\
\text { in virtual laboratory package } \\
\text { are well labeled }\end{array}$ & 22 & 8 & 10 & 1 & 3 & 2.68 & 0.18 & Agree \\
\hline & Average Mean & & & & 2.80 & & & \\
\hline
\end{tabular}

Table 3 shows the mean response of instructional design experts on the users-friendliness of virtual physics laboratory package. The mean response of experts to each of the six items is above 2.50 while the average mean of experts' responses of all the items is 2.80 . This indicates that instructional design experts agreed that the package is user-friendly.

\section{Discussion}

The result of the analysis on novelty of virtual physics laboratory package to physics students and teachers in Nigerian secondary schools indicated that computer experts agreed that virtual laboratory package and concept are new to physics students and teachers in Nigerian secondary schools. The newness of the package to Nigerian school students and teachers is a suggestion that an alternative way of learning physics is available and if employed, students' poor academic achievement in science-subjects could be eradicated.

The results of the analysis on interactivity of VPLP indicated that instructional design experts rated the interactivity of the package low. This is not in line with the recommendation of Bates (1995) that to achieve quality in teaching and learning in education, learning technologies, resources and activities should be made highly interactive. The finding of this study revealed that the package only supports learner-to-content interaction and this is not in agreement with the recommendations of Bates (1995) and Falode (2014) that before any learning package can be said to be highly interactive, it must promote learner-content, learner-instructor, and learner-learner interactions. This finding is also not in agreement with the view of Babateen (2011) who was of the opinion that virtual laboratory should be distinctively interactive and have unique sorts of interaction better than traditional multimedia.

The result of the analysis also indicated that instructional design experts agreed that the virtual physics laboratory package is user-friendly. This is in line with the recommendation of Bates (1995) that learning technologies must be friendly to users and easy to use before they can maximally benefit from such. This finding is also in line with the recommendation of Dillon (2007) that virtual laboratory program should be developed in an interesting and attractive form in order to attract students' attention and urge them to complete the experiment.

\section{Conclusion}

It has been asserted that several learning packages that have been developed to facilitate teaching and learning of practical-based science subjects particularly physics are not being utilized in secondary schools in Nigeria. The major cause of non-utilization of learning technologies is because the packages are not evaluated to satisfy selection criteria after their development and validation. From the findings of the study, it can be concluded that the computer experts agreed that the VPLP was new to students and staff, the instructional design experts agreed that the interactivity of the VPLP and also agreed that the VPLP was user-friendly. The usage will certainly improve students' achievement in Physics if measures are taken to improve the package and make it available in schools.

\section{Recommendations}

Based on the major findings of this study, the following recommendations were made:

1. Developers of learning packages like virtual physics laboratory package should ensure high interactivity and user-friendliness of such packages. This will enhance effective communication and foster students' interest in physics concepts;

2. Teachers and students should embrace new learning technologies like virtual laboratory package in order not to be behind in the usage of effective tools being used in developed countries to enrich teaching and learning processes.

3. Development of computer assisted and multimedia instructions should be integrated into the curriculum of pre-service teachers. This will prepare them and equip them with appropriate skills needed to enrich learning in this computer world.

4. Regular in-service trainings, in forms of seminars, workshops and conferences should be organized for teachers and students in order to keep them abreast of technological innovations that with enhance teaching and learning. 


\section{References}

Atsloom, Z. (2009). E-learning course evaluation proposal using ACTIONS model. Available: www.slideshare.net/u059087/proposal-for-course-evaluation

Babateen, H. M. (2011). The role of virtual laboratories in science education. IACSIT press: Singapore.

Bates, A. W. (1995). Technology, open learning and distance education. Routledge: London.

Cooperstein, S. E. and Kocevar-Weidinger, E. (2004). Beyond active learning: A constructivist approach. Reference Services Review, 32(2): 141-48.

Dillon, S. (2007). Virtual science labs. New York Times: New York.

Falode, O. C. (2014). A Bates' ACTIONS evaluation of virtual laboratory package on selected Nigerian secondary school physics concepts. Unpublished Ph.D. Thesis. Department of Educational Technology, University of Ilorin: Ilorin, Nigeria.

Falode, O. C. and Onasanya, S. A. (2015). Teaching and learning efficacy of virtual laboratory package on selected Nigerian secondary school Physics concepts. Chemistry: Bulgarian Journal of Science Education, 24(4): 572-83.

Falode, O. C. and Gambari, A. I. (2017). Evaluation of virtual laboratory package on Nigerian secondary School Physics concepts. Turkish Online Journal of Distance Education, 18(2): 168-78.

Harry, E. and Edward, B. (2005). Making real virtual lab. The Science Education Review, 4(1): 2-11.

Javed, A. (2005). Importance of Physics highlighted in the international seminar on physics in developing countries. Past, present and future: Islambad - Pakistan.

Mahmoud, A. and Zoltan, K., 2009. "The impact of the virtual laboratory on the hands-on laboratory learning outcomes, a two years empirical study." In 20th Australasian association for Engineering Education Conference. University of Adelaide, 6-9 December, 2009.

Murniza, M., Halimah, B. and Azlina, A. (2010). Virtual laboratory for learning biology - a preliminary investigation. Word Academy of Science Engineering and Technology, 1: 272-575. Available: https://www.researchgate.net/publication/289627154_Virtual_laboratory_for_learning_biology_a_preliminary_investigation

Nunn, J. (2009). The virtual Physics laboratory V 7.0.: Available: www.vplab.co.uk

Okoro, D., 2003. "Physics, technology and sovereignty: The Journey so far." In STAN proceeding of the 14th annual conference. pp. 252-53.

Rafiu, A. A. and Adetona, A. A., 2006. "Obstacles encountered by students in understanding: Basic concepts of physics and new feeling approach to overcome them." In Proceedings of 2nd SSSE Conference, FUT, Minna.

West African Examination Council (2002-5). Chief Examiner report (2002, 2003, 2004, 2005). May/June. 